\title{
Evaluation of Role Played by Mediators of Immediate Hypersensitivity in Exercise-induced Asthma
}

\author{
E. Chandler Deal, Jr., Stephen I. Wasserman, Nicholas A. Soter, \\ R. H. Ingram, Jr., and E. R. MCFADDEN, JR., Departments of Medicine and \\ Divisions of Dermatology of the Peter Bent Brigham and Robert Breck Brigham \\ Divisions of the Affiliated Hospital Center and Harvard Medical School, Boston, \\ Massachusetts 02115
}

\begin{abstract}
A B S T R A C T To determine whether mediators of immediate hypersensitivity played a role in the pathogenesis of exercise-induced asthma, we measured the concentration of histamine and neutrophil-chemotactic activity present in systemic arterial blood during thermal challenges in five asymptomatic asthmatics. Because exercise-induced asthma has been shown to be a result of respiratory heat loss and because respiratory heat loss during isocapnic hyperventilation has been shown to give identical responses, we chose the latter provocational method in order to minimize increases in cardiac output that might interfere with the interpretation of mediator concentrations in arterial blood. Multiple aspects of pulmonary mechanics were also recorded before and after provocation. The results of these studies were then compared with the effects observed when the same subjects inhaled aerosols of specific antigens on the same day. Each challenge produced identical alterations in lung function, and neither was associated with consistent changes in arterial histamine. However, antigen provocation evoked a sustained and prolonged release of neutrophil chemotactic activity in each subject, whereas isocapnic hyperventilation with cold air was without effect. These data strongly suggest that mast-cell derived mediators are not involved in the development or maintenance of the bronchial obstruction that follows exercise in asthmatics.
\end{abstract}

\section{INTRODUCTION}

Although it has been recognized since early in the Christian era that physical exertion could precipitate acute episodes of asthma (1), it has only been within the last several years that fundamental advances have been made into the mechanism underlying this phe-

Received for publication 27 August 1.979 and in revised form 2.9 October 1979. nomenon. The bulk of current evidence demonstrates that the essential initial stimulus for the development of bronchoconstriction is a fall in temperature of the intrathoracic airways secondary to the loss of heat and water that occurs during the conditioning of inspired air $(2-4)$. If heat loss and airway cooling are prevented, obstruction does not develop, and if they are augmented by lowering the inspired air temperature and/or water content, or by increasing the level of ventilation, the obstruction proportionately worsens (2-5). Exercise per se, is not essential and serves only as the means to increase ventilation (4). Thus, the need to search for a humoral substance being released from the working muscles has been eliminated.

Despite these developments, it is not yet known how airway cooling produces its effects. However, there is a series of observations in the literature that suggests that mediators of immediate hypersensitivity may somehow play a role. For example, it is well documented that cromolyn sodium, a drug that stabilizes mast-cell membranes, is effective in blunting exercise-induced asthma (6). Similarly, it has been demonstrated that the magnitude of the obstructive response following repetitive exercise stints decreases if the challenges are performed over short time intervals (7-9), and it has been suggested that this behavior represents depletion of a mediator that requires time to regenerate (8). Finally, it has been shown that physical stimuli such as cold are capable of causing mast cell degranulation with release of mediators in individuals with cold urticaria $(10,11)$, and it is possible that an analogous situation may occur within the airways.

In an effort to determine whether airway cooling is associated with release of the mediators of immediate hypersensitivity, we assayed systemic arterial blood for its content of histamine and for its neutrophil-chemotactic activity during thermal challenges in asthmatics. The results of these studies were then compared with the effects observed when the same subjects were ex- 
posed to aerosols of specific antigens. Our observations form the basis of this report.

\section{METHODS}

Our subjects consisted of five asymptomatic nonsmoking asthmatic individuals who met the criteria of the American Thoracic Society (12). Each had reproducible exercise-induced asthma previously documented in this laboratory and each was atopic as demonstrated by histories of allergic rhinitis and positive skin test reactions to intradermal injection with a variety of allergens (wheal $>10 \mathrm{~mm}$ in response to an injection of 100 protein nitrogen units/ml concentration of allergen). All medications were withheld for $12 \mathrm{~h}$ before any study day and none of our subjects had used cromolyn sodium or glucocorticosteroids for at least $1 \mathrm{mo}$ before these investigations. Informed consent was obtained from each participant.

The pulmonary function endpoints recorded were airway resistance, lung volumes, and spirometry. Resistance and total lung capacity were measured in a constant-volume variablepressure plethysmograph (Warren E. Collins, Inc., Braintree, Mass.) that was serially interfaced to an analogue recorder (Electronics for Medicine, Pleasantville, N. Y.) and a minicomputer (Lab 8E, Digital Equipment Corp., Marlboro, Mass.) $(13,14)$. Resistance was converted to its reciprocal conductance and expressed as a conductance-volume ratio termed specific conductance (15). Five measurements of each variable were recorded and the means computed. These data were considered acceptable if their coefficients of variation were $<5 \%$.

Maximum forced exhalations were performed in triplicate using a waterless spirometer (Searle Cardiopulmonary, Inc., Houston, Tex.) and 1-s forced expiratory volumes $\left(F E V_{1}\right)^{1}$ were computed using standard techniques. The subject's best effort as defined by the curve with the largest vital capacity and $\mathrm{FEV}_{1}$ was used for analysis.

The bronchial challenges employed were isocapnic hyperventilation with cold air and antigen inhalations. Isocapnic hyperpnea was performed using our standard technique in which the seated subject inhales through a heat exchanger and exhales into a 7-liter reservoir balloon that is constantly evacuated through a calibrated rotameter ${ }^{2}$ (4). By instructing the subjects to breathe so as to keep the balloon filled, their minute ventilations precisely match the rate of emptying, and in this fashion minute ventilations can be set and maintained at any desired level. End tidal carbon dioxide tensions were continuously measured at the mouth by a Beckman LB-2 analyzer (Beckman Instruments, Inc., Fullerton, Calif.) and displayed on the oscilloscope of the analog recorder. At the inspiratory port of the exchanger a mixing valve permitted us to supply sufficient $\mathrm{CO}_{2}$ to keep end tidal carbon dioxide tensions constant at resting eucapnic levels, and thus avoid the bronchoconstrictor effects of hypocapnia (16).

Cold air was produced by passing compressed air through the heat exchanger while the latter was externally cooled with circulating isopropyl alcohol maintained at $-35^{\circ}(4,5) .^{2}$ The temperature of the inspired air was constantly recorded by a thermocouple situated within the air stream and located $10 \mathrm{~cm}$ upstream from the mouth.

Preliminary antigen inhalation challenges were performed according to the recommendations of Chai et al. (17). The

\footnotetext{
${ }^{1}$ Abbreviation used in this paper: $\mathrm{FEV}_{1}, 1-\mathrm{s}$ forced expiratory volumes.

${ }^{2}$ Breslin, F. J., E. R. McFadden, Jr., R. H. Ingram, Jr., and E. C. Deal, Jr. Effects of atropine on respiratory heat loss in asthma. J. Appl. Physiol. Respir. Environ. Exercise Physiol. In press.
}

challenge began with five breaths of the antigen concentration required to elicit a $2+-$-intradermal test and was increased in one-half $\log$ increments until the $\mathrm{FEV}_{1}$ fell between 30 and $35 \%$ from its control value. In these studies the diluent was used as a control. All aerosols were generated with a DeVilbiss 42 nebulizer.

Histamine was measured by specific radioenzyme assay sensitive to $0.1 \mu \mathrm{g}(18)$.

To obtain leukocytes for chemotaxis, venous blood from normal individuals was incubated with dextran and citrate anticoagulant, pH 5.2, for $45 \mathrm{~min}$ at $37^{\circ} \mathrm{C}$, to allow sedimentation of the erythrocytes. The leukocyte-rich supernatant fraction was aspirated and suspended in $0.84 \% \mathrm{NH}_{4} \mathrm{Cl}$ to lyse contaminating erythrocytes. The leukocytes then were sedimented at $400 \mathrm{~g}$ for $10 \mathrm{~min}$ at room temperature, washed twice in Hanks' balanced salt solution (Microbiological associates, Walkersville, $\mathrm{Md}$.) containing $0.005 \mathrm{M}$ Tris, $\mathrm{pH} 7.4$, and resuspended at a concentration of 2.4 to $2.8 \times 10^{6}$ in medium 199 (Microbiological Associates) made ().4\% with ovalbumin and 0.005 M Tris, pH 7.4.

Chemotaxis was assessed by a modification (19) of the Boyden chamber assay (20). Micropore filters (Bockman Corporation, Freehold, N. J.) were fixed to polystyrene disposable chambers (Adaps (Corporation, Dedham, Mass.) with $3-\mu \mathrm{m}$ pore size filters employed for chemotactic studies of neutrophilic polymorphonuclear leukocytes. The lower compartment was filled with $1 \mathrm{ml}$ of buffer or of dilutions of the material being assessed for chemotactic activity. Chemotaxis was carried out for $2.5-3 \mathrm{~h}$ at $37^{\circ} \mathrm{C}$ in moist chambers. The cell response was determined by counting the cells at a fixed distance into the stained filters. This distance was selected to achieve background counts in the absence of a chemotactic stimulus of zero to six cells for neutrophilic leukocytes. The cells then were counted without knowledge of the protocol in five high-power fields from each of the duplicate filters, and these values were expressed as the mean net cells per high-power field per milliliter of chemotactic factor by correction for spontaneous migration and additional controls. The mean values of the duplicate filters differed by $<20 \%$.

On the day of study an arterial catheter was inserted percutaneously into the radial artery under local anesthesia. Approximately $30 \mathrm{~min}$ later the subjects underwent a challenge with $4 \mathrm{~min}$ of isocapnic hyperventilation as described above. A 2 -h recovery period then ensued during which time pulmonary mechanic's returned to base line. After this had been accomplished the subjects inhaled a predetermined quantity of antigen. The level of ventilation and the dose of antigen used were adjusted for each subject based upon previous studies to produce equivalent degrees of obstruction. Arterial bloods were drawn before and at 1, 3, 5, 10, 15, 20, and 30 min after each provocation. The samples from each experiment were encoded, and analyzed in duplicate, in a blind fashion for their concentrations of histamine and their neutrophilchemotactic activity. Pulmonary mechanic's were measured before and at 5-10 min after completion of each challenge.

The data were analyzed by paired $t$ tests.

\section{RESULTS}

Table I contains individual anthropometric and challenge data. Our subjects consisted of three men and two women with a mean age of $24 \mathrm{yr}$. In the hyperventilation study the mean inspired air temperature was $-11^{\circ} \mathrm{C}$. Minute ventilation averaged 83 liters $/ \mathrm{min}$ and end tidal carbon dioxide tension was $38 \mathrm{~mm} \mathrm{Hg}$. In the antigen provocation the average dose given the group was 26 breath units. 
TABLE I

Anthropometric and Challenge Data

\begin{tabular}{|c|c|c|c|c|c|c|c|c|}
\hline \multirow[b]{2}{*}{ Subject } & \multirow[b]{2}{*}{ Age } & \multirow[b]{2}{*}{ Sex } & \multicolumn{3}{|c|}{ Hyperventilation } & \multicolumn{3}{|c|}{ Antigen } \\
\hline & & & $\mathrm{Ti}$ & $\dot{\mathrm{V}}_{\mathrm{E}}$ & $\mathrm{PetCO}_{2}$ & Allergen & Concentration & Breath Units \\
\hline TW & 28 & $\mathbf{M}$ & -10 & 94 & 39 & Cat & $1: 1,000$ & 12 \\
\hline $\mathbf{M H}$ & 24 & $\mathrm{~F}$ & -10 & 70 & 39 & Cat & $1: 1,000$ & 10 \\
\hline $\mathrm{ML}$ & 24 & $\mathrm{~F}$ & -11 & 70 & 40 & Ragweed & $1: 100$ & 30 \\
\hline MR & 19 & $\mathbf{M}$ & -8 & 90 & 36 & Cat & $1: 100$ & 30 \\
\hline $\mathrm{MC}$ & 24 & $\mathbf{M}$ & -15 & 89 & 38 & Alternaria & $1: 100$ & 50 \\
\hline Mean & 24 & - & -11 & 83 & 38 & - & - & 26 \\
\hline SD & 3 & - & 3 & 12 & 2 & - & - & 16 \\
\hline
\end{tabular}

$\mathrm{Ti}$, inspired air temperature in ${ }^{\circ} \mathrm{C} ; \dot{\mathrm{V}}_{\mathrm{E}}$, minute ventilation in liters per minute; PetCO, $\mathrm{C}_{2}$, end tidal carbon dioxide tension in millimeters of hemoglobin; Concentration, weight/volume; Breath Units, concentration $\times$ number of breaths inhaled.

Fig. 1 contrasts the changes in pulmonary mechanics observed in both challenges. The thermal burden induced by hyperventilation with cold air produced significant alterations in lung function. Specific conductance and $F E V_{1}$ fell an average of 74 and $48 \%$ from their base-line values, respectively, whereas residual volume rose $95 \%$. These effects were all statistically significant at the 0.001 level. Exposure to antigen produced similar changes. Specific conductance and $\mathrm{FEV}_{1}$ now decreased 67 and $37 \%$ respectively, and residual volume increased $78 \%$. Although the response to this challenge was slightly smaller than that observed in the thermal provocation, the differences between the two did not reach statistical significance. Similarly, there were no significant differences between the pre-challenge lung function for either study.

The mediator data are contained in Figs. 2 and 3. In the case of histamine (Fig. 2) we were unable to measure any consistent changes in systemic arterial blood that suggested that this mediator was released into the circulation with either challenge, nor were we able to find any differences between challenges. However,

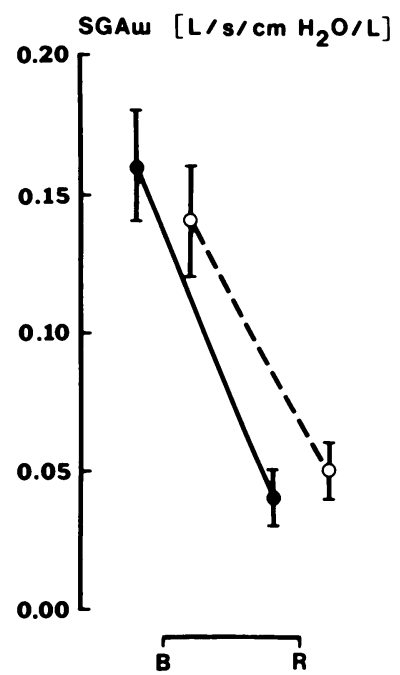

COMPARISONS

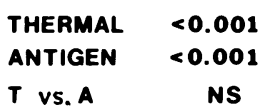

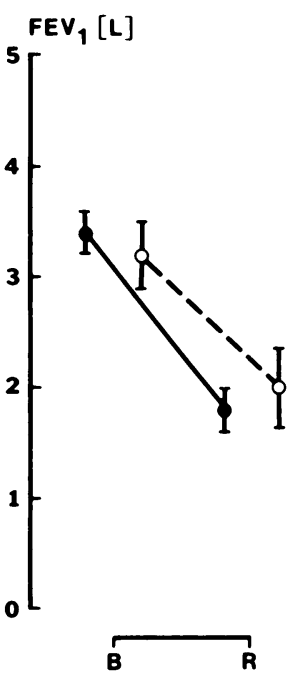

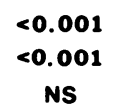

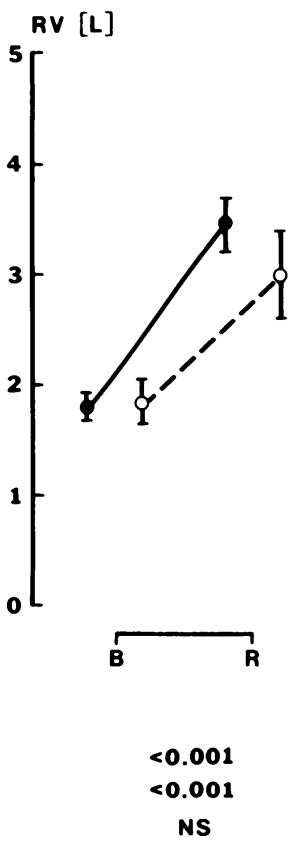

FIGURE 1 Comparative effects of thermal and antigen challenges on pulmonary mechanics. The data points are mean values and the brackets represent one standard error. SGaw, specific conductance; $\mathrm{FEV}_{1}$, 1-s forced expiratory volume, and $\mathrm{RV}$, residual volume. The letters $\mathrm{B}$ and $\mathrm{R}$ below each graph indicate base line and the postchallenge response data, respectively. $-\bullet$ - thermal; $\bigcirc-\bigcirc$, antigen. 


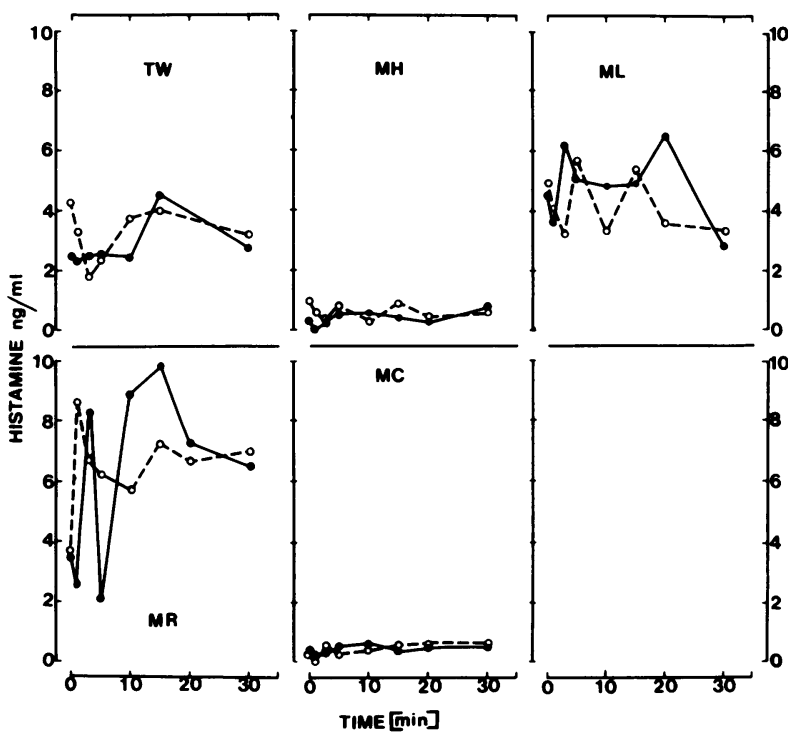

FIGURE 2 Histamine concentrations in arterial blood with antigen and thermal provocations. Zero time refers to the baseline prechallenge observation.

this was not the case with serum neutrophil-chemotactic activity. As shown in Fig. 3, in each subject antigen provocation evoked a sustained and prolonged increase of neutrophil-chemotactic activity in concert with the changes in lung function. Increased chemotactic activity was observed within $1 \mathrm{~min}$ of challenge, peaked at $5 \mathrm{~min}$, and persisted for at least $30 \mathrm{~min}$. Isocapnic hyperventilation with cold air was without effect.

\section{DISCUSSION}

The results of this study clearly demonstrate that even though antigen and thermal challenges to the airways of asthmatics elicit the same degree of obstruction, these provocations are distinctly different in their association with measurable mediators in systemic arterial blood. Because exposure to antigen results in a kinetic release of neutrophil chemotactic activity, and airway cooling does not, we would suggest that different mechanisms account for these two responses. The observed effects of antigen provocation are quite similar to those reported from other laboratories $(21,22)$ and are compatible with antigen-antibody interactions at the surface of mast cells in the airway with subsequent release of the mediators of immediate hypersensitivity. Although we recognize the possibility that some of the neutrophilchemotactic activity that we recorded could have arisen from the participation of circulating basophils in the reaction, we deem this source to be quite unlikely. The time-course of release of the molecule found in the current experiment is quite similar to that which has been documented to occur in other immunoglobulin
(Ig)E mast-cell mediated disorders $(10,11,23,24)$. Thus, although the molecular weight of the presently described molecule is not yet known, its release kinetics suggest that the likely source is from the mast cell. In contrast, the failure to demonstrate such liberation with a thermal challenge performed in the same subjects on the same day suggests that mast-cell derived mediators are not involved in the pathogenesis of exercise-induced asthma.

The validity of these conclusions depends heavily upon the equivalency of hyperventilation and exercise. As mentioned in the introduction, it has been shown that the stimulus for airway constriction in exerciseinduced asthma is respiratory heat loss, irrespective of how that loss is produced (2-4). Specifically, it is now documented that both the degree of airway cooling and the magnitude of the subsequent bronchoconstriction evoked by isocapnic hyperventilation exactly mirror that which follows exercise when ventilation, and inspired air temperatures and water contents are matched $(4,25) .^{2}$ In addition, recent experiments have established that the effects of drugs, such as atropine and cromolyn sodium, on the obstructive response induced by either means are identical (26). ${ }^{2}$ Thus, there is ample evidence that these two stimuli are interchangeable. In fact, on two subjects in this study, both isocapnic hyperventilation and exercise were performed as separate challenges, and no differences were observed in either the mechanical or mediator results.

Similarly, it is unlikely that our findings were biased by the study design. Performing both challenges on the same day eliminated any variations that spontaneous fluctuations in the underlying disease process may have induced, and the use of frigid air ensured the largest possible degree of obstruction in the thermal challenge $(4,5,26)$. Based upon the data in the literature, we anticipated detecting mediators in the peripheral circulation with the antigen provocation, but were unsure as to what to expect with airway cooling. Although several recent abstracts have suggested that histamine may be found in increased quantities in systemic blood following exercise in some asthmatics (27-29), none of these studies has presented release kinetics, and the results were highly inconsistent between subjects. More importantly, none of them has controlled for the fact that an elevation in blood histamine during or after exercise may be entirely nonspecific, and may result from the increased quantity of histamine-containing cells that accompanies the leukocytosis of physical exertion (30). Those investigations that have examined this matter more thoroughly have uniformly found negative results for histamine and other mediators $(31,33)$. Nonetheless, because we did not know how long it would take to resynthesize or replenish mast cell contents once they had been released, we reasoned that if airway cooling were the initial challenge of each day, our chances of obtaining 


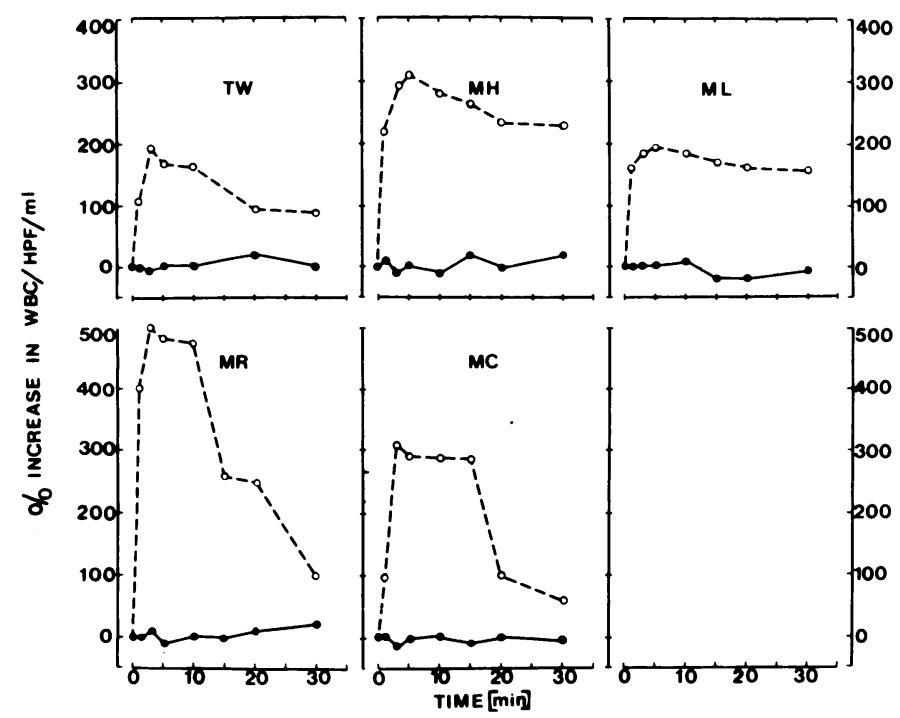

Figure 3 Serum neutrophil-chemotactic activity after antigen and thermal provocation. The format is identical to Fig. 2. HPF, high-powered field; IVBC, white blood cells.

positive results would be optimized. Thus, this approach would, if anything, have prejudiced the results against what was found.

Although there were random elevations in arterial blood histamine after both thermal and antigen challenges in some subjects, there was no kinetic release noted after either form of provocation (Fig. '2). The failure to find a correlation between histamine release after antigen exposure is disappointing, but has been demonstrated previously in both animals and man. Chiesa and colleagues (34) detected histamine in arterial plasina of dogs after bronchoprovocation; however, they also noted that significant bronchoconstriction could be induced with dilute concentrations of antigens without producing measurable histamine levels. Reed and associates noted a similar phenomenon in humans and were unable to find measurable changes in circulating histamine with antigen challenges. ${ }^{3}$

We do not believe that our inability to detect histamine in this study is the result of technical problems with the assay inasmuch as we have previously measured the release kinetics of this molecule in patients with idiopathic cold-induced urticaria $(10,11)$, cholinergic urticaria (24), and idiopathic solar urticaria (23). One explanation for these apparent discrepancies is that although it is possible to measure histamine in a local circulation, draining an experimentally challenged site, such as the skin, it may well be that its rapid metabolism precludes detection of appreciable quantities at sites far removed from the original reaction.

One obvious point of caution in linking mediators

\footnotetext{
${ }^{3}$ C. E. Reed. Personal communication.
}

measured in arterial blood to an airway response is that the local tissue concentrations might not be well reflected by those found in the circulation. Although this is undoubtedly true, in order to explain the positive results with antigen in combination with negative results with airway cooling, it would be necessary to invoke either a larger degree of mediator release or greater increases in the premeability of the tissue barriers between mast cells and blood after antigen. With equivalent degrees of obstruction, it is difficult to accept that there is a greater quantity of mediators involved in the antigen response if mediators caused both responses. With regard to differences in permeability between challenges, we are aware of no data in support of the possibility.

An additional possibility to consider is that antigen challenge might have produced more widely distributed changes in the tracheobronchial tree than did the thermal stimulus, resulting in greater mediator release on that basis. However, we would then need to postulate that the greater distribution of antigen effects involved lung regions that did not contribute to the degree of obstruction because functional derangements resulting from the two challenges were identical. Although we cannot reject this possibility, it is difficult for us to imagine what portion of the tracheobronchial tree would undergo change without making an additional contribution to at least one of the measurements of obstruction. Hence, we think this possibility to be unlikely.

Another possible factor is the effect of an increase in cardiac output, which undoubtedly occurs with isocapnic hyperventilation, on our ability to measure mediators in arterial blood. If the amount of mediator 
released per unit time was the same with the two challenges, an increase in cardiac output would result in a smaller concentration of that mediator in an arterial sample taken at a point in time. Although this proposal would explain a difference in peak concentrations, it would not account for the striking differences in neutrophilic chemotactic activity found between challenges for periods up to $30 \mathrm{~min}$, because cardiac output would have returned toward control values early in the posthyperventilation period.

If, as the present study suggests to us, mediators are either not involved or play only a minimal role in the production of exercise-induced asthma, we must deal with two previous observations thought to support the idea that mediators are involved. These are the protective role of disodium cromoglycate and the refractory period seen after repeated exercise. With regard to disodium cromoglycate, although its major effect is thought to be stabilization of mast cells, it has also been shown to have a phosphodiesterase-inhibiting action (35). Thus, it is possible that this drug might influence smooth muscle activity directly.

With respect to the refractory period, little has been done to delineate the mechanism and the mediator depletion hypothesis is only one of several. It is possible that ventilations are different in repeated exercise bouts or that there may be a persistent sympatho-adrenal response between closely spaced stints. In any event, the results of the current investigation indicate that further studies are now required to define the mechanism underlying the apparent refractoriness of airways to repeated exercise in asthmatics and the actual mechanisms by which drugs alter the response.

\section{ACKNOWLEDGMENTS}

This work was supported in part by Research Career Development Award HL-00013 (Dr. McFadden), Young Investigator Award AI 14292 (Dr. Soter), Allergic Diseases Academic Award AI 00254 (Dr. Wasserman), grants HL-17873, HL-17382, HL07010, AI 07722, AI 10356, and RR 05669 from the National Institutes of Health.

\section{REFERENCES}

1. Adams, F. 1856. The Extant Works of Aretaeus the Cappodician. Sydenham Society, London. p. 316.

2. Strauss, R. H., E. R. McFadden, Jr., R. H. Ingram, Jr., E. C. Deal, Jr., and J. Jaeger. 1978. Influence of heat and humidity on the airway obstruction induced by exercise in asthma. J. Clin. Invest. 61: 433-440.

3. Deal, E. C., Jr., E. R. McFadden, Jr., R. H. Ingram, Jr., R. H. Strauss, and J. J. Jaeger. 1979. Role of respiratory heat exchange in production of exercise-induced asthma. J. Appl. Physiol. Respir. Environ. Exercise Ph!siol. 46: 467-475.

4. Deal, E. C., Jr., E. R. McFadden, Jr., R. H. Ingram, Jr., and J. J. Jaeger. 1979. Hyperpnea and heat flux: initial reaction sequence in exercise-induced asthma. $J$. Appl. Physiol. Respir. Environ. Exercise Physiol. 46: 476-483.

5. Strauss, R. H., E. R. McFadden, Jr., R. H. Ingram, Jr., and J. J. Jaeger. 1977. Enhancement of exercise-induced asthma by cold air breathing. N. Engl. J. Med. 297: 743-747.

6. Haynes, R. L., R. H. Ingram, Jr., and E. R. McFadden, Jr. 1976. An assessment of the pulmonary response to exercise in asthma and an analysis of the factors influencing it. Am. Rev. Respir. Dis. 114: 739-752.

7. McNeil, R. S., J. R. Nairn, J. S. Millar, and C. G. Ingram. 1966. Exercise-induced asthma. Q. J. Med. 35: 55-67.

8. Edmunds, A. T., M. Tooley, and S. Godfrey. 1978. The refractory period after exercise-induced asthma: its duration and relation to the severity of exercise. Am. Rev. Respir. Dis. 117: 247-254.

9. James, L., J. Faciane, and R. M. Sly. 1976. Effect of treadmill exercise on asthmatic children. J. Allergy Clin. Immunol. 57: 408-416.

10. Soter, N. A., S. I. Wasserman, and K. F. Austen. 1976. Cold urticaria: release into the circulation of histamine and eosinophil chemotactic factor of anaphylaxis during cold challenge. N. Engl. J. Med. 294: 687-690.

11. Wasserman, S. I., N. A. Soter, D. M. Center, and K. F Austen. 1977. Cold urticaria. Recognition and characterization of a neutrophil chemotactic factor which appears in serum during experimental cold challenge. J. Clin. Invest. 60: 189-196.

12. American Thoracic Society. 1962. Definition and classification of chronic bronchitis, asthma and pulmonary emphysema. Am. Rev. Respir. Dis. 85: 762-768.

13. DuBois, A. B., S. Y. Botelho, G. N. Bedell, R. Marshall, and J. H. Comroe, Jr. 1956. A rapid plethysmographic method for measuring thoracic gas volume: a comparison with a nitrogen washout method for measuring functional residual capacity in normal subjects. J. Clin. Invest. 35: $322-326$.

14. Sykes, W. T., R. L. Haynes, and E. R. McFadden, Jr. 1977. On line determination of lung volumes by phethysmography and digital computer. Am. Rev. Respir. Dis. 115: 581-585.

15. Briscoe, W. A., and A. B. DuBois. 1958. The relationship between airway resistance, airway conductance, and lung volume in subjects of different age and body size.J. Clin. Invest. 37: 1279-1285.

16. Newhouse, M. T., M. R. Becklake, P. T. Macklem, and M. McGregor. 1964. Effect of alterations in end-tidal $\mathrm{CO}_{2}$ tensions on flow resistance.J. Appl. Physiol. 19: 745-749.

17. Chai, H., R. S. Farr, L. A. Froehlich, D. A. Mathison, J. A. McLean, R. R. Rosenthal, A. L. Sheffer, S. L. Spector, and R. G. Townley. 1975. J. Allerg! Clin. Immunol. 56: 323-327.

18. Beaven, M. A., S. Jacobsen, and Z. Horakova. 1972. Modification of the enzymatic isotope assay of histamine and its application to measurement of histamine in tissues, serum and urine. Clin. Chim. Acta. 37: 91-103.

19. Goetzl, E. J., and K. F. Austen. 1972. A neutrophil immobolizing factor derived from human leukocytes. 1. Generation and Partial Characterization.J. Exp. Med. 136: 1564-1580.

20. Boyden, S. 1962. The chemotactic effect of mixtures of antibody and antigen on polymorphonuclear leukocytes. J. Exp. Med. 115: 453-466.

21. Atkins, P. C., M. Norman, H. Weiner, and B. Zweiman. 1977. Release of neutrophil chemotactic activity during immediate hypersensitivity reactions in humans. Ann. Intern. Med. 86: 415-418.

22. Atkins, P. C., M. E. Norman, and B. Zweiman. 1978. Antigen-induced neutrophil chemotactic activity in man. Correlation with bronchospam and inhibition of disodium cromoglycate. J. Allerg! Clin. Immunol. 62: 149-155. 
23. Soter, N. A., S. I. Wasserman, M. A. Pathak, J. A. Parrish, and K. F. Austen. 1979. Solar urticaria: release of mast cell mediators into the circulation after experimental challenge. J. Invest. Dermatol. 72: 282. (Abstr.)

24. Soter, N. A., S. I. Wasserman, K. F. Austen, and E. R. McFadden, Jr. 1979. Mast cell mediator release in vivo and alterations in lung function in patients with cholinergic urticaria. Clin. Res. 27: 245A. (Abstr.)

25. Deal, E. C., Jr., E. R. McFadden, Jr., R. H. Ingram, Jr., and J. J. Jaeger. 1979. Esophageal temperature during exercise in asthmatic and non-asthmatic subjects. J. Appl. Physiol. Respir. Environ. Exercise Physiol. 46: 484-490.

26. Deal, E. C., Jr., E. R. McFadden, Jr., R. H. Ingram, Jr., and J. J. Jaeger. 1978. Effects of atropine on the potentiation of exercise-induced bronchospasm by cold air. $J$. Appl. Physiol. Respir. Environ. Exercise Physiol. 45: 238-243.

27. Anderson, S. D., L. Ferris, D. M. Temple, D. Allen, and D. C. Lindsay. 1978. Arterial blood histamine and cyclic AMP levels in exercise-induced asthma. Am. Rev. Respir. Dis. 117: 55 (Abstr.)

28. Simon, R. A., M. Ginsberg, R. M. Timms, and D. D. Stevenson. 1979. Exercise-induced bronchospasm: a study of plasma mediators. J. Allerg! Clin. Immunol. 63: 31 . (Abstr.)

29. Karr, R. M., B. B. Brach, M. R. Wilson, V. Anicetti, and
J. E. Salvaggio. 1979. Change in levels of arterial blood histamine during exercise-induced asthma. J. Allerg!y Clin. Immunol. 63: 32. (Abstr.)

30. Duner, H., and B. Pernow. 1958. Histamine and leukocytes in blood during muscular work in man. Scand. J. Clin. Lab. Invest. 10: 394-396.

31. Granderos, G., B. G. Simonsson, B. E. Skoogh, and H. Wetterquist. 1971. Exercise-induced bronchoconstriction and histamine release. Scand. J. Respir. Dis. 52: 131-136.

32. Field, J., J. Allegra, J. Trantlein, L. Demers, M. Gillin, and R. Zelis. 1976. Measurement of plasma prostaglandins during exercise-induced bronchospasm. J. Allerg! Clin. Immunol. 58: 581-585.

33. Anderson, S. D., R. Pojer, I. D. Smith, and D. Temple. 1976. Exercise-related changes in plasma levels of 15Keto-13,14-dihydro-prostaglandin F2 $\alpha$ and noradrenaline in asthmatic and normal subjects. Scand. J. Respir. Dis. 57: $41-48$.

34. Chiesa, A., D. Dain, G. L. Meyers, G. F. Kessler, and W. M. Gold. 1975. Histamine release during antigen inhalation in experimental asthma in dogs. Am. Rev. Respir. Dis. 111: 148-156.

35. Taylor, W. A., D. H. Francis, I). Sheldon, and I. M. Roitt. 1974. Antiallergic actions of disodium chromoglycate and other drugs known to inhibit cyclic $3^{\prime}, 5^{\prime}$-nucleotide phosphodiesterase. Int. Arch. Allerg! Appl. Immunol. 47: $175-193$ 